\title{
Effect of lithium thiocyanate addition on the structural and electrical properties of biodegradable poly(E-caprolactone) polymer films
}

\author{
M. Ravi, S.H. Song \\ Shenzhen Key Laboratory of Advanced Materials, Department of \\ Materials Science and Engineering, Shenzhen Graduate School, Harbin Institute of \\ Technology, Shenzhen 518055, China \\ M. Gu, J.N. Tang \\ College of Materials Science and Engineering, Shenzhen University, Shenzhen 518060, \\ China \\ Z. Y. Zhang \\ Advanced Polymer and Composites (APC) Research Group, School \\ of Engineering, University of Portsmouth, \\ Portsmouth, Hampshire PO1 3DJ, UK
}

\begin{abstract}
Polymer electrolyte films of biodegradable poly( $\varepsilon$-caprolactone) (PCL) doped with LiSCN salt in different weight ratios were prepared using solution cast technique. The effect of crystallinity and interaction between lithium ions and carbonyl groups of PCL on the ionic conduction of PCL:LiSCN polymer electrolytes was characterized by X-ray diffraction (XRD), optical microscopy, Fourier transform infrared spectroscopy (FTIR) and AC impedance analysis. The XRD results revealed that the crystallinity of the PCL polymer matrix decreased with an increase in LiSCN salt concentration. The complexation of the salt with the polymer and the interaction of lithium ions with carbonyl groups of PCL were confirmed by FTIR. The ionic conductivity was found to increase with increasing salt concentration until $15 \mathrm{wt} \%$ and then to decrease with further increasing salt concentration. In addition, the ionic conductivity of the polymer electrolyte films followed an Arrhenius relation and the activation energy for conduction decreased with increasing LiSCN concentration up to $15 \mathrm{wt} \%$. UV-vis absorption spectra were used to evaluate the optical energy band gaps of the materials. The optical energy band gap shifted to lower energies with increasing LiSCN salt concentration.
\end{abstract}

\section{Keywords}

Polymer electrolytes XRD Interaction behavior Ionic conduction Electrical properties

\section{Introduction}

Ion-conducting solid polymer electrolytes have received considerable interest due to their technological significance and impact in the domain of solid-state ionic device applications $[\underline{1}, \underline{2}, \underline{3}, \underline{4}, \underline{5}, \underline{6}]$. Solid polymer electrolytes (SPEs) are usually prepared by different chemical method such as solution casting and hot pressing. In these methods, metal salts and high molecular weight polymer host are dissolved in a common solvent. The metal salts with low charge density anion are easily dissolved in the host polymer due to its low lattice energy, making the polymer-salt complex formed easily for the preparation of solid polymer electrolytes. Hence, these metal salts are generally used as dopants in the preparation of SPEs. The ionic transport in these polymer electrolytes is associated with the metal salt dissolution and the coupling between the ions and segmental motions of the 
polymer chains. The SPEs have several advantages over conventional liquid electrolytes, such as improved safety, enhanced capacity, leakage free, low cost, light weight, and easy fabrication $[\underline{7}, \underline{8}]$. For most of the ionic device applications, it is desirable that the SPEs display an excellent ionic conductivity, dimensional stability, processibility, and flexibility under ambient conditions.

Some investigations have been focused on several types of polymers as the host for the polymer-based electrolytes, such as poly (ethylene oxide; PEO), poly(vinylidence fluoride), poly(methyl methacrylate), poly(vinyl chloride) and poly(vinyl acetate), and poly (vinyl pyrrolidone) $[\underline{9}, \underline{10}, \underline{11}]$. These polymers are not biodegradable and have several drawbacks, such as long biodegradable time, poor mechanical strength, and high sensitivity to moisture. Due to their long biodegradable time, they will create environmental problems such as global warming and large wastage. These drawbacks limit their usages in different applications. Consequently, it is a challenge to develop SPEs which are environmentfriendly and exhibit high ionic conductivity and good mechanical stability. As is well known $[12,13]$, poly ( $\varepsilon$-caprolactone) (PCL) is a biodegradable polyester-based polymer with a melting point of approximately $60{ }^{\circ} \mathrm{C}$ and its glass transition temperature is around $-60{ }^{\circ} \mathrm{C}$. It is derived from crude oil and prepared by ring opening polymerization of $\varepsilon$ caprolactone using a stannous octoate as catalyst. Due to its low glass transition temperature, the polymer chain exhibits segmental motion which can help ions transport from one complexation site to another. In addition, PCL possesses a carbonyl group which can easily coordinate cations, and thus its mechanical strength is quite high [14]. Hence, PCL may be chosen as a promising polymer host for preparation of polymer electrolytes $[15,16]$. Lithium salts are widely used as a dopant in the polymer-salt complexed electrolytes due to its low lattice energy, cost, atomic mass, atomic radius, etc. It can be dissolved easily, producing ions for ionic conduction in polymer electrolytes. The lithium salt-complexed polymer electrolytes are developed by co-ordination interaction between ions and polymer structure. These complexed polymer electrolytes exhibit better chemical, thermal and electrical properties in comparison with other alkali metal salts-complexed polymer electrolytes.

Some research work has been reported on utilizing biodegradable PCL as the polymer host for different complexed polymer electrolyte systems such as PCL-metal salts $[\underline{17}, \underline{18}, \underline{19}, \underline{20}]$. These complexed polymer electrolytes have an environment-friendly nature, good flexibility and high thermal stability. The obtained maximum electrical conductivity values in different systems were $1.1 \times 10^{-7} \mathrm{~S} \mathrm{~cm}^{-1}$ for the PCL-12 wt\% $\mathrm{LiBF}_{4}[\underline{17}], 5.9 \times 10^{-9} \mathrm{~S} \mathrm{~cm}^{-1}$ for the d-PCL $(530)_{20} \mathrm{Mg}\left(\mathrm{CF}_{3} \mathrm{SO}_{3}\right)_{2}$ at $24{ }^{\circ} \mathrm{C}[\underline{18}]$, $3.7 \times 10^{-7} \mathrm{~S} \mathrm{~cm}^{-1}$ for the d-PCL $(530)_{6.1} \mathrm{Li}^{+} / \mathrm{Eu}^{3+} \mathrm{CF}_{3} \mathrm{SO}_{3}$ at $20{ }^{\circ} \mathrm{C}[19]$, and $4.01 \times 10^{-6} \mathrm{~S} \mathrm{~cm}^{-1}$ for the d-PCL(530) $0.5 \mathrm{LiCF}_{3} \mathrm{SO}_{3}$ at $35{ }^{\circ} \mathrm{C}$ [20]. As seen, PCL-lithium salt complexed polymer electrolyte systems usually exhibit higher ionic conductivity values compared to other systems. It is widely recognized that the ionic conduction of solid polymer electrolytes depends upon the weight ratio of inorganic salt to polymer as well as the nature of the salt. This is due to the transfer efficiency of charge carriers and the complex formation between the ions and the polymer matrix. Hence, the crystallinity effect and polymer-ion interaction behavior also play a key role in increasing the ionic conductivity of polymer-lithium salt complexed polymer electrolytes. Until now, no research outcomes have been reported regarding the effect of crystallinity and interaction behavior on the ionic conduction of the PCL:lithium thiocyanate salt complexed polymer electrolytes, which was aimed to do in the present work. The lithium thiocyanate (LiSCN) is a good dopant because it is thermally stable, nontoxic and insensitive to ambient 
moisture as compared to other lithium salts. Lithium can easily donates (loses) electrons to become a positive $\mathrm{Li}^{+}$which has a small ionic radius $(0.9 \AA)$ and the presence of thiocyanate in the lithium salt is a good anion of choice.

In this work, the LiSCN was used as the dopant salt to fabricate PCL-based polymer electrolyte films with the following research objective: To clarify the changes in the structural and electrical properties of biodegradable PCL polymer films with the addition of LiSCN salt using X-ray diffraction (XRD), optical microscopy, Fourier transform infrared spectroscopy (FTIR), and alternating current (AC) impedance spectroscopy.

\section{Experimental}

Materials

The PCL with $\mathrm{Mn}=80 \mathrm{kDa}$ was purchased from Sigma Aldrich and used as received. Its molecular weight was 80,000. LiSCN was obtained from Sigma Aldrich and dried for $24 \mathrm{~h}$ at $45{ }^{\circ} \mathrm{C}$ in an oven and stored in desiccators prior to use. Chloroform with a purity of $99 \%$ (Sigma Aldrich) was used as the common solvent for the preparation of complexed polymer electrolytes.

\section{Preparation of thin solid polymer electrolyte films}

Pure PCL and PCL:LiSCN complexed polymer electrolyte films with different LiSCN concentrations $(5,10,15$, and $20 \mathrm{wt} \%)$ were prepared using a standard solution casting technique. Initially, the PCL was added to chloroform in the required quantity by stirring magnetically at ambient temperature for complete dissolution. Pre-determined amounts (5, 10,15 , and $20 \mathrm{wt} \%$ ) of LiSCN salt were separately dissolved in chloroform and added to the PCL polymer solution under continuous stirring for $12 \mathrm{~h}$. Finally, viscous solutions were poured into glass petri dishes, and thus, chloroform was allowed to evaporate slowly at room temperature to obtain free-standing polymer films at the bottom of dishes. The films were dried at room temperature for $6 \mathrm{~h}$ to remove any traces of the residual solvent in the polymer films. The obtained films were stored in the vacuum desiccators to avoid any environmental moisture absorption prior to subsequent characterization. The thickness of these films was determined by mechanical stylus method using German made "Perthometer" and was found to be approximately $130 \mu \mathrm{m}$ with an accuracy of approximately $\pm 5 \mu \mathrm{m}$. The film was self-standing and semi-transparent in nature as shown in Fig. 1. It had good flexibility and did not snap upon appreciable manual bending or stretching. 


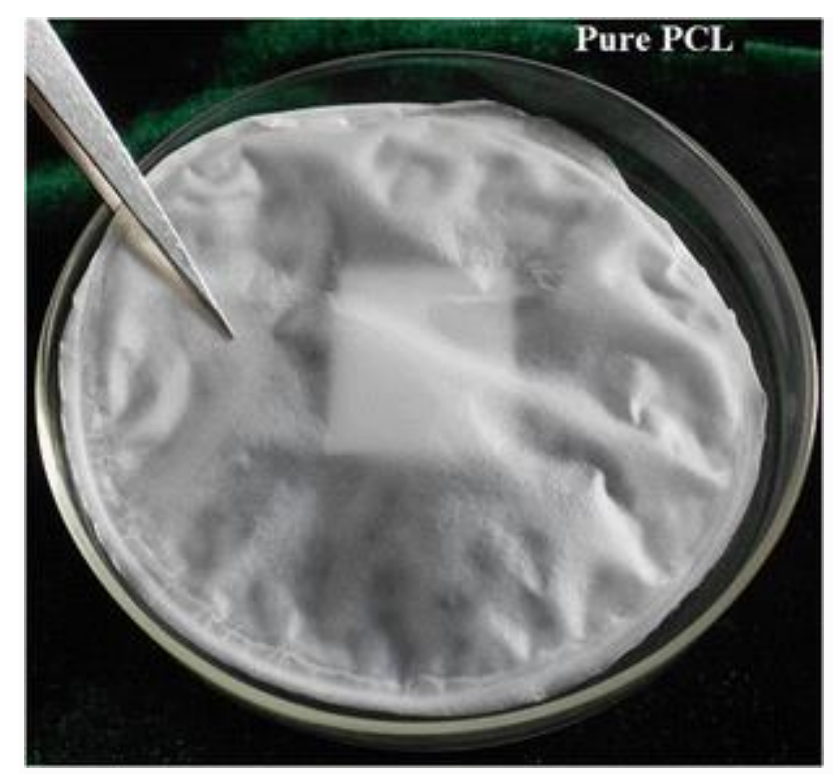

Fig. 1

Macroscopic morphology of the pure PCL polymer film

\section{Characterization}

Structural characterization of the polymer films involves XRD, optical microscopy (OM), and FTIR. To study the structural characteristics such as crystal structure, crystallite size, and crystallinity of polymer films, XRD analysis was carried out using a D/max Rigaku Xray diffractometer with $\mathrm{Cu} \mathrm{K} \mathrm{K}_{\alpha}$ radiation $(\lambda=1.5406 \AA)$ at ambient temperature. Surface morphology and microscopic feature of the polymer films was examined using optical microscopy. The chemical composition of polymer host and its possible interaction with the dopant salt was studied by FTIR spectra using a Nicolet 380 spectrometer with an optical resolution of $2 \mathrm{~cm}^{-1}$. AC impedance spectroscopy is a well-established method to study the electrical properties of polymer films. In the present study, the impedance measurements were performed using a computer-controlled Solartron SI $1255 \mathrm{HF}$ frequency analyzer along with Solartron 1296 dielectric interface. All the measurements were undertaken in the frequency and temperature range $0.1 \mathrm{~Hz}-1 \mathrm{MHZ}$ and $303-333 \mathrm{~K}$, respectively. In the measurements, the polymer films were cut into circular pieces and sandwiched between two stainless steel electrodes, which were placed inside the temperature-controlled furnace.

Band structure of the polymer film was studied using optical absorption spectra by virtue of a Perkin Elmer Lambda 950 UV-vis-NIR spectrophotometer in the wavelength range of 200-600 $\mathrm{nm}$ at room temperature.

\section{Results and discussion}

Structural analysis

Figure $\underline{2}$ shows the XRD patterns of pure PCL, LiSCN salt, and PCL:LiSCN complexed polymer electrolyte films. The XRD pattern of LiSCN salt exhibits sharp peaks, indicating the crystalline nature of the lithium salt. The observed peaks are well matched with JCPDS card No. 38-0603. The XRD pattern of pure PCL exhibits three significant sharp crystalline peaks at $2 \theta=21.4^{\circ}, 22.0^{\circ}$, and $23.7^{\circ}$ which are assigned to the (110), (111), and (200) orientation planes, respectively. Several low peaks are also observed at around $29.78^{\circ}$, $36.02^{\circ}$, and $38.4^{\circ}$. The sharp peaks are attributed to the crystalline phase of PCL, which originates from the ordering of polymer side chains due to the intermolecular interaction 
between PCL chains through the hydrogen bonding. These crystalline peaks are overlapped on a broad hump between $15^{\circ}$ and $25^{\circ}$, indicating amorphous contribution. These observations confirm that the PCL polymer system possesses a semi-crystalline nature and its crystal structure is orthorhombic [21].

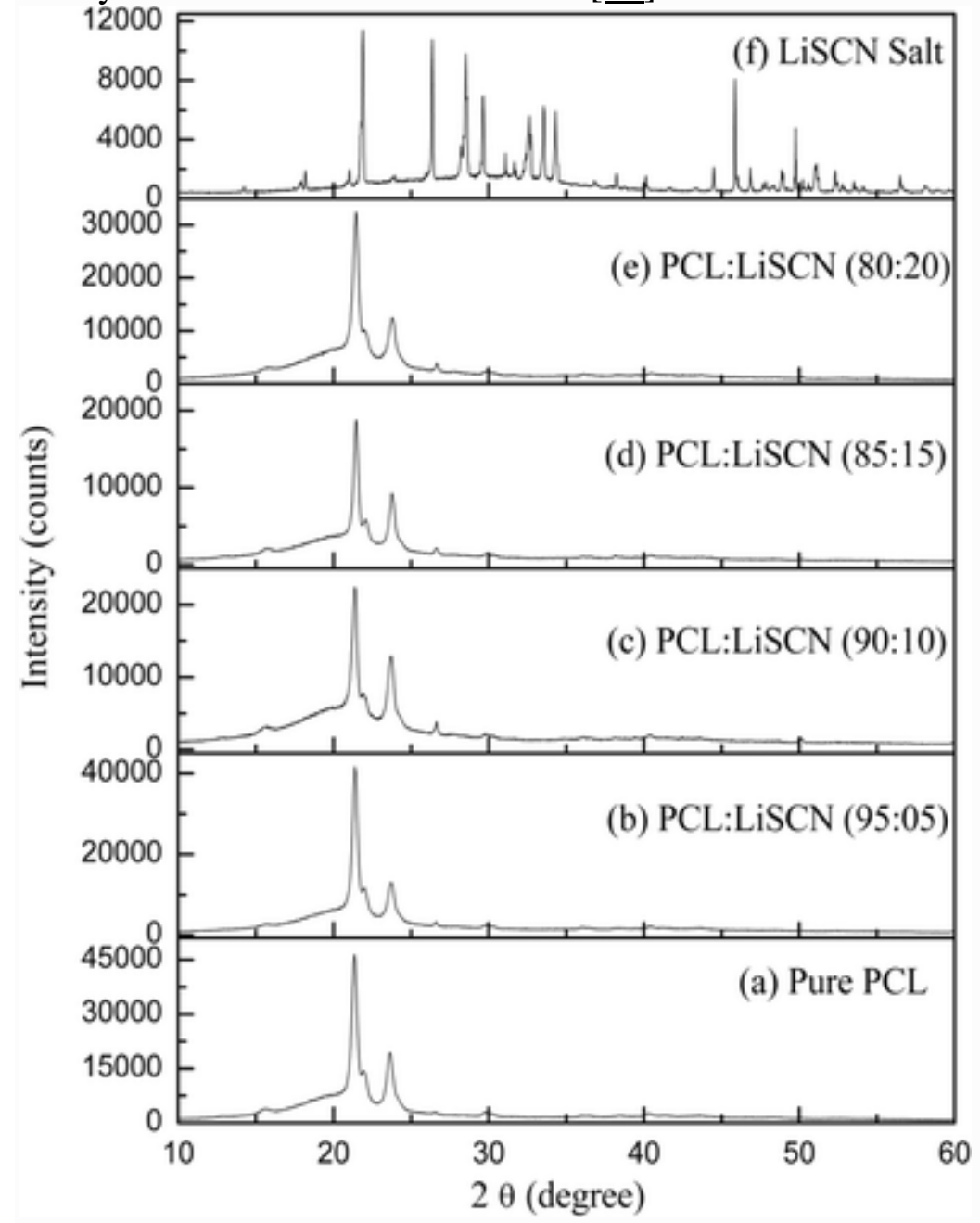

Fig. 2

XRD patterns of pure PCL, LiSCN salt, and PCL:LiSCN complexed polymer electrolytes

The comparative study reveals that, when the LiSCN salt is incorporated into the polymer matrix, the intensities of all crystalline peaks decrease with an increase of LiSCN concentration up to $15 \mathrm{wt} \%$, suggesting an increase in the amorphicity of the polymer electrolytes. This could be due to the disruption of the semi-crystalline structure of the polymer by salt dissolution. When the LiSCN salt dissolves in the polymer host, the interaction between the PCL matrix and LiSCN leads to a decrease in the intermolecular interaction among the polymer chains, thereby reducing the crystalline phase and hence increasing the amorphous region. The intensity of the peak at around $2 \theta=21.4$ for the 80PCL:20LiSCN electrolyte is relatively higher than that for the 85PCL:15LiSCN electrolyte, showing the high degree of crystallinity in the $20 \mathrm{wt} \% \mathrm{LiSCN}$ complexed polymer system. Furthermore, the crystalline peaks are slightly shifted and the intensity of the peak at $26.68^{\circ}$ increases with increasing salt concentration, indicating the complex formation. These observations confirms that the polymer-salt (PCL-LiSCN) complexation and the suppression of crystallinity in the host PCL polymer. 
The polymer film average crystallite size $(L)$ is calculated from the full-width halfmaximum (FWHM) using the Scherrer's formula

$\mathrm{L}=\mathrm{c} \lambda / \mathrm{B} \cos \theta$

where $c$ is the Scherrer constant (0.94), $B$ is the FWHM (in radians) of the peak, $\lambda$ is the Xray wavelength (1.5406 $\AA$ for $\mathrm{Cu} \mathrm{K}_{\alpha}$ radiation), and $\theta$ is the Bragg diffraction angle.

Generally, the average crystallite size is found to be in the range of $22-26 \mathrm{~nm}$ as depicted in Table $\underline{1}$, showing nano crystalline grains embedded in the amorphous matrix.

\section{Table 1}

Degree of crystallinity $\left(X_{\mathrm{c}}\right)$ and crystallite size in PCL:LiSCN polymer electrolytes

\begin{tabular}{|l|l|l|}
\hline Sample & $\boldsymbol{X}_{\mathbf{c}}(\boldsymbol{\%})$ & Crystallite size (nm) \\
\hline Pure PCL & 42.42 & 24.78 \\
\hline PCL:LiSCN (95:05) & 37.43 & 25.92 \\
\hline PCL:LiSCN (90:10) & 28.37 & 24.02 \\
\hline PCL:LiSCN (85:15) & 26.28 & 23.17 \\
\hline PCL:LiSCN (80:20) & 33.58 & 23.75 \\
\hline
\end{tabular}

In order to separate the sharp crystalline peaks from the continuous amorphous spectrum, all polymer electrolyte XRD patterns are deconvoluted using peak separation software (Origin Pro 8). Baseline correction has been made prior to fitting multi peaks using Gaussian distribution. Figure $\underline{3}$ illustrates a deconvoluted XRD pattern of PCL:LiSCN (95:05) complex. The sharp and narrow peaks indicate the crystalline phase while the broad peak indicates the amorphous phase. Clearly, the combined fitting is in good consistent with the measured one. The area under the deconvoluted peaks is used to calculate the degree of crystallinity $\left(X_{\mathrm{c}}\right)$ in the polymer films by [22]

$\mathrm{Xc}=\mathrm{Ac} / \mathrm{AT} \times 100$

where $A_{\mathrm{c}}$ is the area under the three crystalline peaks and $A_{\mathrm{T}}$ is the total area under all the peaks including both the crystalline and amorphous peaks. The calculated average crystallite size and $X_{\mathrm{c}}$ values are listed in Table 1 . The $X_{\mathrm{c}}$ value of pure PCL is $\sim 42.42 \%$, which is slightly lower as compared to the differential scanning calorimetry result ( 46.9\%) obtained by Khatiwala et al. [23]. This difference could be due to the absence of re-crystallization effect in the XRD patterns [24]. The $X_{\mathrm{c}}$ value decreases gradually with increasing salt concentration until $15 \mathrm{wt} \%$ and then increases with further increasing salt concentration, achieving a minimum value of approximately $26.28 \%$. The reduction in the degree of crystallinity can be ascribed to the inhibition of crystallization by the dissolved ions. The polymeric chain in amorphous phase is more flexible, which results in the enhancement of segmental motion in the polymer. When the LiSCN salt concentration exceeds $15 \mathrm{wt} \%$, both the intensity of crystalline peaks (Fig. 1e) and the $X_{\mathrm{c}}$ value increases. This may be attributed to the reorganization of the polymer matrix. 


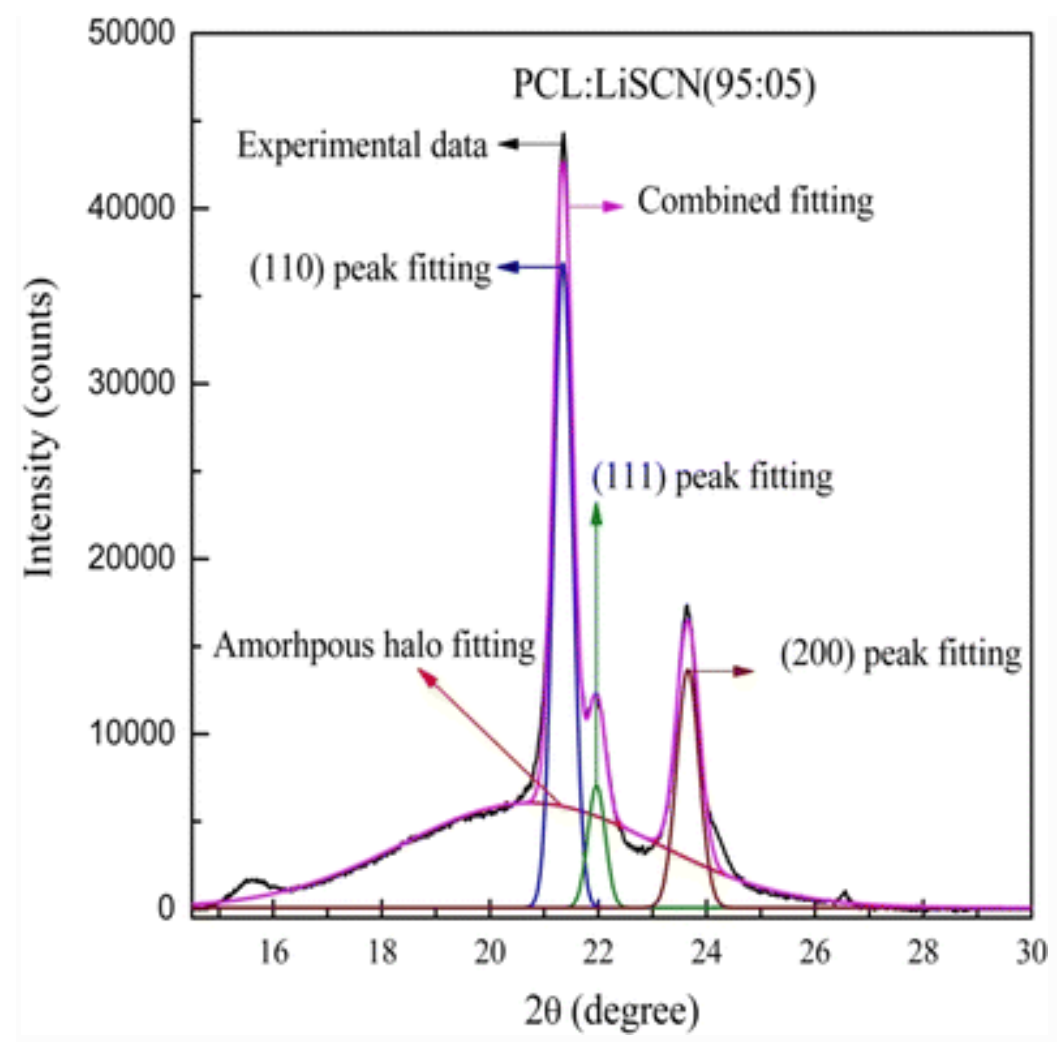

Fig. 3

Deconvoluted XRD patterns of the PCL:LiSCN (95:05) polymer electrolyte film

$\underline{\text { Surface analysis }}$

OM was used to understand the crystalline behavior and their related surface morphology of the polymer films. Figure $\underline{4}$ shows the optical micrographs of pure PCL film and PCL:LiSCN complexes with different LiSCN concentrations. Typical spherulitic texture along with dark boundaries can be seen in the pure PCL film, demonstrating its semicrystalline nature. This type of surface morphology was also observed for other semicrystalline polymers, such as $(\mathrm{PEO})_{6}: \mathrm{NaPO}_{3}$ and $\mathrm{PEO}: \mathrm{Mg}\left(\mathrm{CF}_{3} \mathrm{SO}_{3}\right)_{2}$ polymer electrolytes $[\underline{25}, 26]$. The spherulitic texture in the polymer film shows its lamellar crystalline nature and the dark boundaries indicate the amorphous content in the polymer (Fig. 4a). The lamellar was developed through regular polymer chains folding, leading to a long range order. The lamella radiate out from a central nucleating point. The amorphous phase occupies the regions between the lamella so that the spherulites are embedded in the amorphous matrix. These inter and intra spherulitic amorphous regions may or may not be of the same composition and exhibit distinct physical properties [27]. With the addition of LiSCN salt in the PCL polymer matrix, there are significant surface morphology changes (see Fig. $4 \mathrm{~b}, \mathrm{c}$ ). It is seen that the dark boundary regions increase with increasing LiSCN content up to $15 \mathrm{wt} \%$, indicating an increase in the amorphous content in the polymer-salt complexes. In addition, the surface of spherulites becomes smoother with increasing salt concentration, showing an increase in intra-spherulitic amorphous phase. This reduction in crystallinity has also been confirmed above by the XRD results. When the salt concentration exceeds $15 \mathrm{wt} \%$, the dark boundary regions are reduced along with the increment in lamellae texture. This is due to the reorganization of the polymer matrix (see Fig. $\underline{4 d}$. 

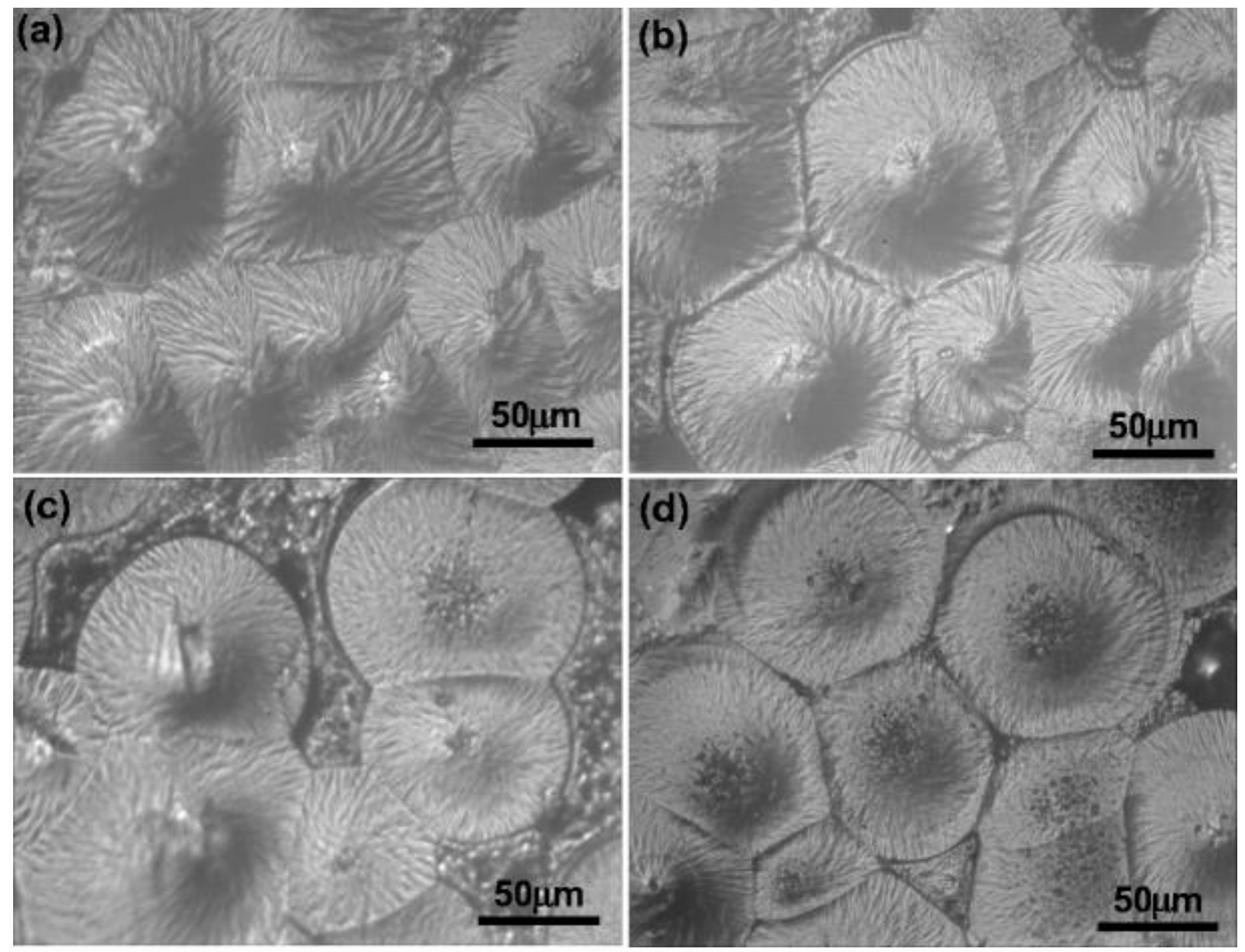

\section{Fig. 4}

Optical micrographs of pure PCL and PCL:LiSCN complexed polymer electrolyte films with different LiSCN contents: a pure PCL, b $5 \mathrm{wt} \% \mathrm{LiSCN}$, c $15 \mathrm{wt} \% \mathrm{LiSCN}$, and $\mathbf{d} 20 \mathrm{wt} \% \mathrm{LiSCN}$

\section{Complexation and interaction analysis}

FTIR spectroscopy has been widely recognized as a powerful tool to identify the detailed molecular structures of polymer and their interaction with dopant salts [28, 29]. Figure $\underline{5}$ shows the FTIR spectra of pure PCL, LiSCN and PCL:LiSCN complexes of various compositions in the wave number range of $650-2,200 \mathrm{~cm}^{-1}$. From the FTIR spectra, the vibrational bands are identified and their assignments are presented in Table $\underline{2}[\underline{21}, \underline{30}]$. The characteristic vibrational bands of LiSCN salt at 1,630,1,401, and $937 \mathrm{~cm}^{-1}$ disappear in the spectra of complexed polymer films. This could be due to the disruption of the initial order of pure PCL polymer structure by the salt [31]. 


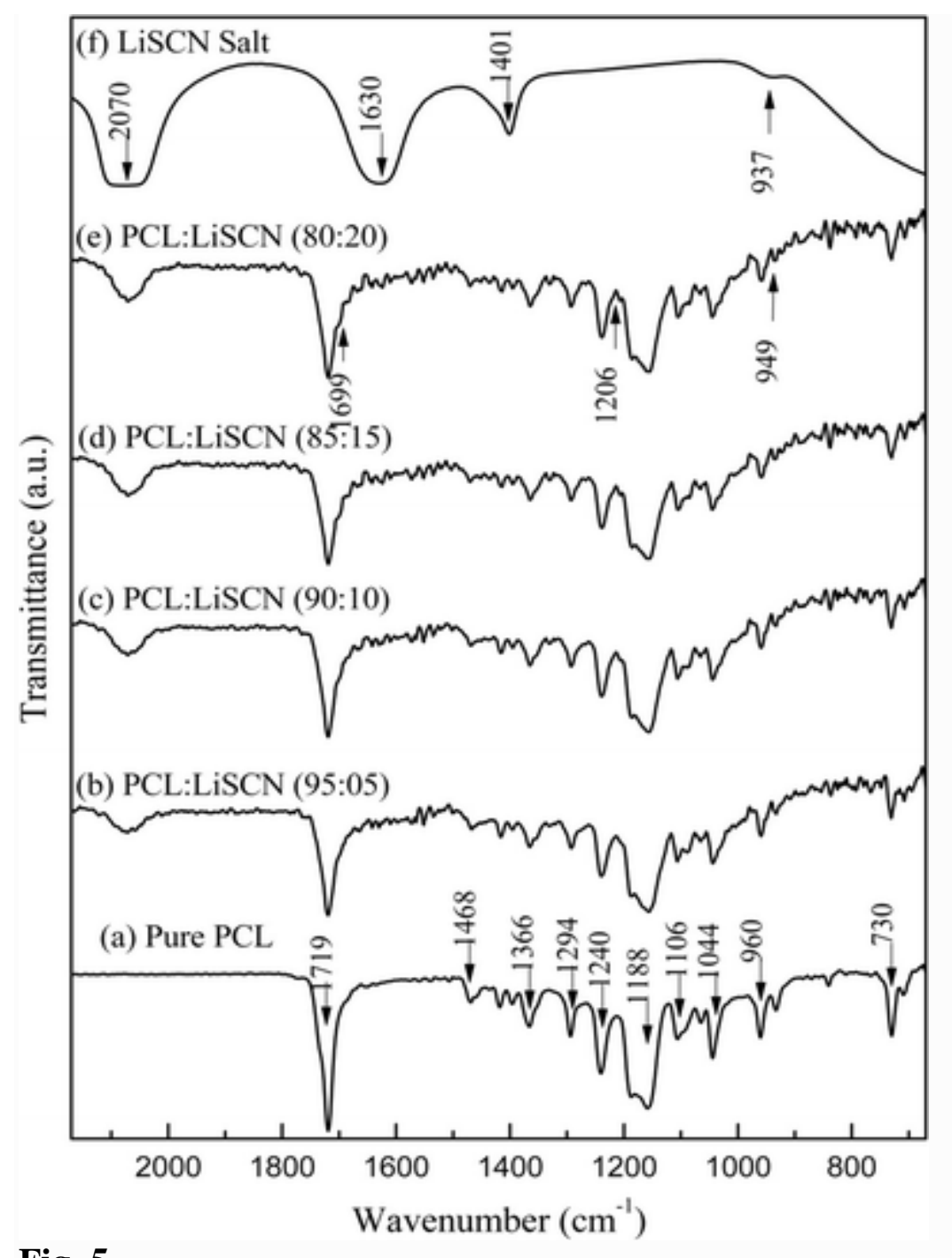

Fig. 5

FTIR spectra of pure PCL, LiSCN salt, and PCL:LiSCN complexed polymer electrolytes 
Table 2

Characteristic infrared bands of pure PCL, LiSCN, and PCL:LiSCN (85:15)

\begin{tabular}{|c|c|c|c|}
\hline \multirow[t]{2}{*}{ Band assignment } & \multicolumn{3}{|c|}{ Band position (wavenumber, $\mathrm{cm}^{-1}$ ) } \\
\hline & Pure PCL & $\begin{array}{l}\text { PCL:LiSCN } \\
(85: 15)\end{array}$ & LiSCN \\
\hline Asymmetric $\mathrm{C}-\mathrm{N}$ & & 2,070 & 2070 \\
\hline $\begin{array}{l}\mathrm{C}=\mathrm{O} \text { stretching amorphous } \\
\text { phase }\end{array}$ & 1,735 & - & \\
\hline $\begin{array}{l}\mathrm{C}=\mathrm{O} \text { stretching crystalline } \\
\text { phase }\end{array}$ & 1,719 & 1,719 & \\
\hline $\mathrm{Li}+$ bonded $\mathrm{C}=\mathrm{O}$ stretching & - & 1,669 & \\
\hline Asymmetric $\mathrm{C} \equiv \mathrm{N}$ stretching & - & - & 1,630 \\
\hline $\mathrm{C}-\mathrm{H}$ scissoring deformation & 1,468 & 1,470 & \\
\hline $\begin{array}{l}\mathrm{C}-\mathrm{H} \text { symmetric } \\
\text { deformation }\end{array}$ & 1,366 & 1,364 & \\
\hline $\begin{array}{l}\mathrm{C}-\mathrm{O} \text { and } \mathrm{C}-\mathrm{C} \text { stretching in } \\
\text { crystalline phase }\end{array}$ & 1,294 & 1,293 & \\
\hline \multirow{2}{*}{$\begin{array}{l}\text { Asymmetric } \mathrm{C}-\mathrm{O}-\mathrm{C} \\
\text { stretching }\end{array}$} & 1,240 & 1,238 & \\
\hline & - & 1,206 & \\
\hline $\mathrm{O}-\mathrm{C}-\mathrm{O}$ stretching & 1,188 & 1,185 & \\
\hline $\begin{array}{l}\mathrm{C}-\mathrm{O} \text { and } \mathrm{C}-\mathrm{C} \text { stretching in } \\
\text { amorphous Phase }\end{array}$ & 1,158 & 1,155 & \\
\hline $\mathrm{C}-\mathrm{O}$ stretching & 1,106 & 1,105 & \\
\hline $\mathrm{C}-\mathrm{C}$ stretching & 1,044 & 1,045 & \\
\hline Symmetric SCN bending & - & - & 937 \\
\hline $\begin{array}{l}\mathrm{C}-\mathrm{O}-\mathrm{C} \text { symmetric } \\
\text { stretching }\end{array}$ & 960 & 958 & \\
\hline $\begin{array}{l}\text { SCN-bonded } \mathrm{C}-\mathrm{O}-\mathrm{C} \\
\text { stretching }\end{array}$ & - & 949 & \\
\hline $\mathrm{CH}_{2}$ rocking & 730 & 730 & \\
\hline
\end{tabular}


As can be seen in Fig. $\underline{5}$, some vibrational bands of pure PCL $(1,366,1,240,1,188$, and $960 \mathrm{~cm}^{-1}$ ) are shifted to lower wave numbers in the PCL:LiSCN complexes and the intensities of most of the vibrational bands for PCL decrease with increasing LiSCN concentration. Moreover, some new vibrational bands $\left(2,070,1,699,1,206\right.$, and $\left.949 \mathrm{~cm}^{-1}\right)$ emerge and some other vibrational bands $\left(1,735 \mathrm{~cm}^{-1}\right)$ vanish in the complexed polymer electrolytes, indicating the formation of polymer-salt complexes.

The carbonyl group $(\mathrm{C}=\mathrm{O})$ in the PCL polymer structure is very sensitive to the complexation with $\mathrm{Li}^{+}$and $\mathrm{SCN}^{-}$ions. Hence, it can be used to probe interaction of salt with the polymer matrix. Since $\mathrm{Li}^{+}$is an electrophile, it always attracts electron-rich atom to interact. In the PCL structure, the oxygen atoms of carbonyl groups $\left({ }^{-\delta} \mathrm{C}=\mathrm{O}^{\delta+}\right)$ have a strong electron donor nature, thereby making their interaction with $\mathrm{Li}^{+}$ions. Fourier infrared spectrum is an effective tool to monitor such an ionic interaction of complexed polymer films. In this study, carbonyl stretching regions of FTIR patterns are used to identify the interaction between $\mathrm{Li}^{+}$and $\mathrm{C}=\mathrm{O}$ in PCL:LiSCN complexes. The roomtemperature FTIR spectra of pure PCL and PCL:LiSCN complexes are showed in Fig. $\underline{6}$, which indicate pronounced carbonyl stretching regions between 1,780 to $1,680 \mathrm{~cm}^{-1}$. When LiSCN is increased in concentration, the free carbonyl band at $1,719 \mathrm{~cm}^{-1}$ broadens gradually, and a new band appears as a shoulder at $1,699 \mathrm{~cm}^{-1}$ which indicates the coordination between the $\mathrm{Li}^{+}$and oxygen atom on the $\mathrm{C}=\mathrm{O}$ group of the PCL [32]. The relative intensity of this new band increases with the increase in LiSCN salt content. This is because that the " $\mathrm{Li}^{+}$bonded" $\mathrm{C}=\mathrm{O}$ groups of the polymer electrolyte increase in conjunction with a decrease in "free" $\mathrm{C}=\mathrm{O}$ groups.

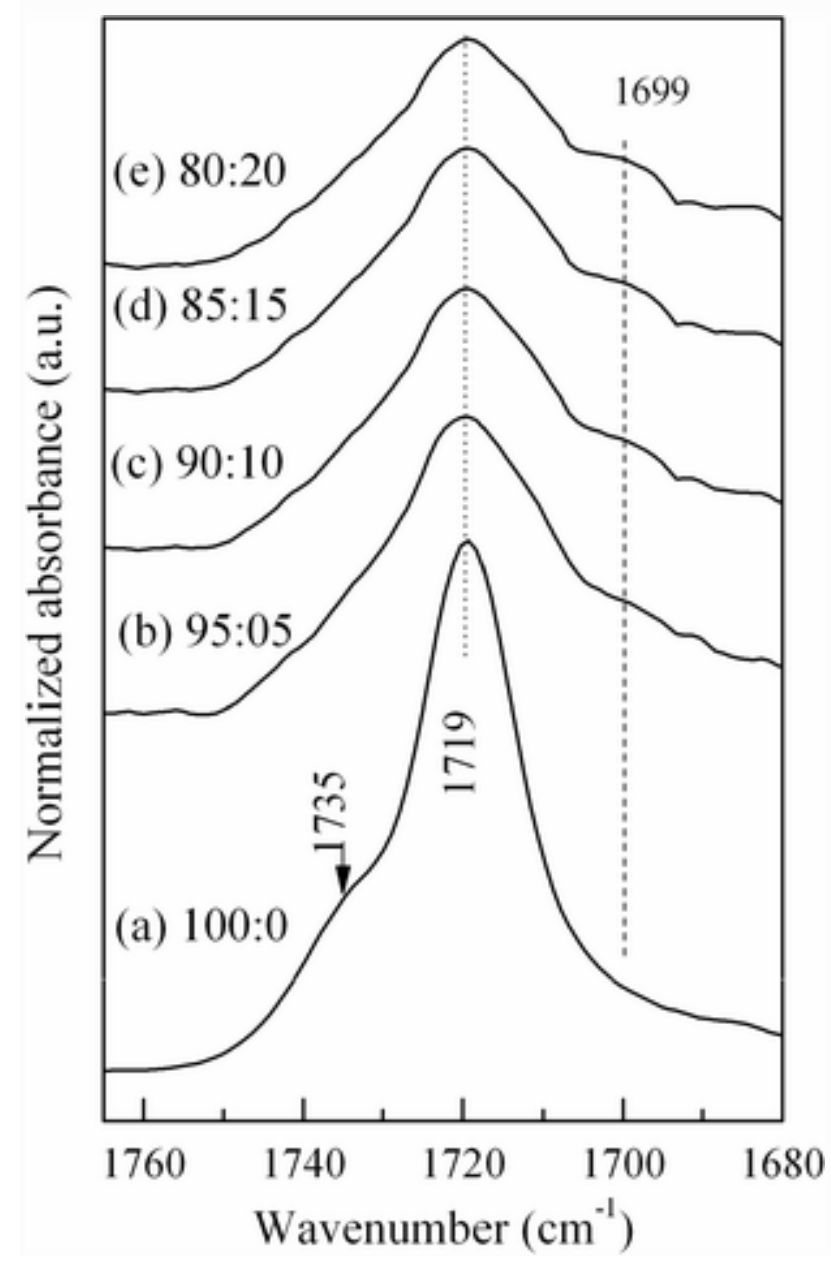


Fig. 6

The $\mathrm{C}=\mathrm{O}$ stretching of PCL:LiSCN complexes in different weight ratios

Similarly, $\mathrm{SCN}^{-}$ion is a nucleophile which easily interacts with electron deficient atom $\left({ }^{-\delta} \mathrm{C}=\mathrm{O}^{\delta+}\right)$, i.e., only one electron deficient atom in the PCL polymer is a carbonyl carbon, which makes a possible interaction with the carbonyl carbon of the PCL polymer chain. On the basis of the aforementioned analysis, the $\mathrm{Li}^{+}$and $\mathrm{SCN}^{-}$ions are believed to interact with the PCL matrix as proposed in Fig. 7.

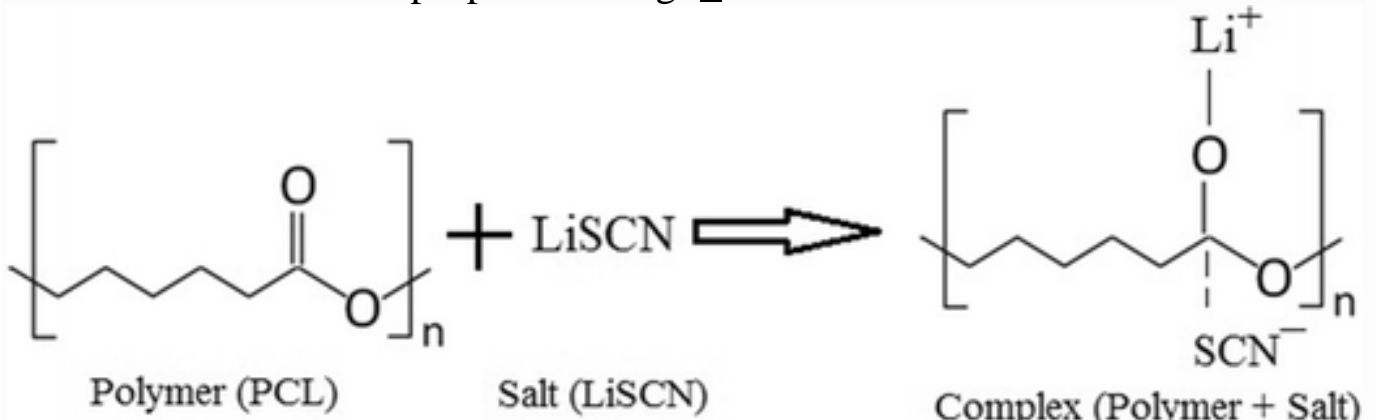

Fig. 7

Structural interaction of poly( $\varepsilon$-caprolactone) and salt (LiSCN)

The FTIR spectrum for pure PCL shows a free carbonyl stretching band at $1,735 \mathrm{~cm}^{-1}$ and a

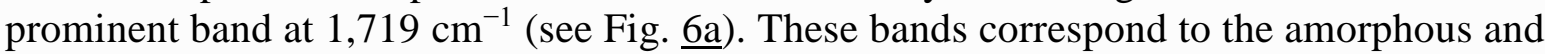
crystalline conformation of PCL [21]. It is found that the crystalline band of pure PCL becomes broadening with increasing LiSCN content. This is due to the partial decay of the crystalline nature of PCL with the addition of salt. The band broadening in the

FTIR/RAMAN spectra is an indication of increase in the amorphous nature of the host polymer [33]. It is well known that when the LiSCN salt is added to the PCL polymer, it introduces ions $\left(\mathrm{Li}^{+}\right.$and $\left.\mathrm{SCN}^{-}\right)$to the polymer matrix, thereby improving the amorphous nature of the host polymer due to the polymer-salt interaction. The PCL polymer semicrystalline nature and its amorphosity increase with the addition of salt have also been confirmed in XRD and OM analyses.

As is well known, the free $\mathrm{Li}^{+}$ions have more mobility than the free $\mathrm{SCN}^{-}$ions due to their small radius. The interaction of carbonyl oxygen with $\mathrm{Li}^{+}$ions might assist the cations to transport through the polymer chains. In the PCL:LiSCN complexed polymer electrolyte systems, the $\mathrm{Li}^{+}$ion transport may take place through the carbonyl oxygen centers of PCL by inter and intra chain ion hopping in the process of segmental mobility. At the lower LiSCN concentration, the interaction between $\mathrm{Li}^{+}$ion and carbonyl oxygen atom is weak due to more available carbonyl $(\mathrm{C}=\mathrm{O})$ vacancy sites for the $\mathrm{Li}^{+}$ions to move in the polymer structure, i.e., the $\mathrm{Li}^{+}$ionic mobility is high. When the LiSCN concentration increases, the interaction between $\mathrm{Li}^{+}$ions and oxygen atoms in $\mathrm{C}=\mathrm{O}$ groups of PCL becomes stronger and may get saturated at $15 \%$ LiSCN. This may be the optimum environment for the $\mathrm{Li}^{+}$ion transport in the PCL matrix. The highest amorphocity is also observed for the $15 \mathrm{wt} \% \mathrm{LiSCN}$ complexed polymer film in the XRD and OM analyses. As the salt concentration exceeds $15 \%$, the $\mathrm{Li}^{+}$ion mobility decreases due to the strong interaction with $\mathrm{C}=\mathrm{O}$ groups and the reduction in the number of free $\mathrm{Li}^{+}$ions. This means that there could be a large number of ion pairs $\left(\mathrm{Li}^{+}-\mathrm{SCN}^{-}\right)$and ion triplets $\left(\mathrm{Li}^{+}-\mathrm{SCN}^{-}-\mathrm{Li}^{+}\right)$in the polymer matrix. These ion pairs and ion triplets hinder the ion transport and block the segmental motion of the polymer chins. Consequently, the overall conductivity may be decreased. Further details of ion conduction in the PCL:LiSCN polymer systems were studied by AC impedance analysis. 
Recently, Woo et al. [34] prepared the PCL based proton conducting polymer electrolyte films and studied their structural and electrical properties by virtue of XRD, FTIR, DSC, and impedance spectroscopy. The XRD results reveal that the pure PCL possesses the semicrystalline structure and its degree of crystallinity decreases with increasing $\mathrm{NH}_{4} \mathrm{SCN}$ salt content. It is obtained that the degree of crystallinity of pure PCL and 74PCL:26NH $4 \mathrm{SCN}$ are 40.06 and 37.06, respectively. From the FTIR results, the complexation of salt with polymer is confirmed. Obviously, the present results are well consistent with theirs.

\section{Ionic conduction analysis}

AC impedance spectroscopy has been widely used to investigate ionic conductivity of solid polymer electrolytes films. Figure $\underline{8}$ shows the Nyquist impedance plots of the $10 \mathrm{wt} \%$ LiSCN complexed PCL polymer electrolyte at different temperatures. Clearly, on each plot, there is a depressed semicircular arc in the high frequency range, which may be attributed to the combined behavior of mobile ions and polymer matrix. This is equivalent to a parallel combination of bulk resistance and bulk capacitance. In addition, an inclined straight line exists in the low frequency range which represents the blocking double layer capacitance $\left(C_{\mathrm{dl}}\right)$ near the electrode-electrolyte interface formed by the ion migration. In the present polymer samples, the ion transport seems to be taking place through the sites of unequal potential wells since the semicircle is depressed [35]. Furthermore, the roughness of the electrode-electrolyte interface leads to inclination of the straight line at an acute angle to the real axis [36]. The diameter of the depressed semicircle shrinks with rising temperature, indicating an activated conduction mechanism.

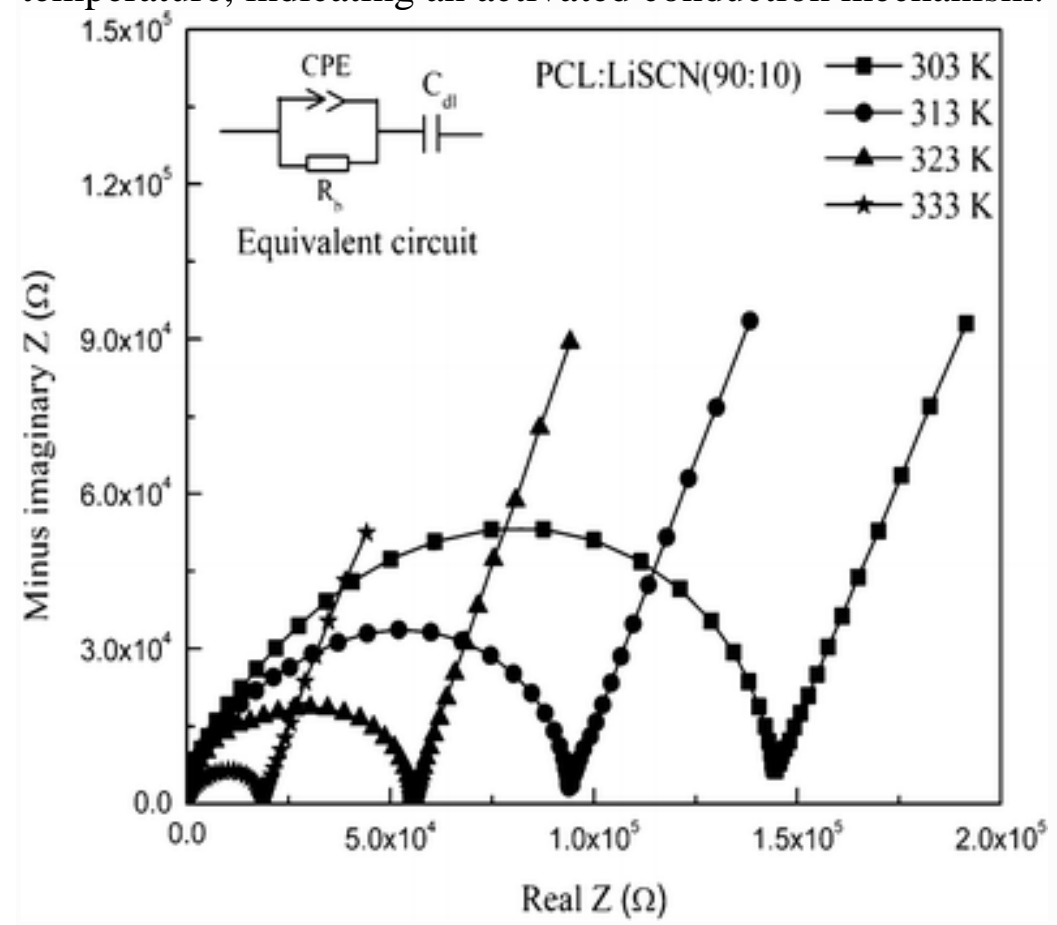

Fig. 8

Nyquist impedance plots of the PCL:LiSCN (90:10) polymer electrolyte film at different temperatures with an equivalent circuit as the inset

The magnitude of blocking double-layer capacitance $\left(C_{\mathrm{dl}}\right)$ will be obtained from any position on the straight line portion using the equation: $Z_{\mathrm{W}}=1 /\left(2 \pi f C_{\mathrm{dl}}\right)$, where $Z_{\mathrm{W}}$ is the impedance corresponding to the position and $f$ is the frequency. At room temperature, the value of the capacitance at the electrode-electrolyte interface is obtained as $\sim 1 \mu \mathrm{F}$ at $1 \mathrm{~Hz}$, it can be attributed to the electrode polarization. The impedance plots of the present 
samples are modeled by the equivalent circuit as shown in the inset of Fig. $\underline{8}$. In this equivalent circuit, $R_{\mathrm{b}}$ is the bulk resistance of the samples and CPE (constant phase element) is the non-ideal capacitor, which accounts for the depressed semicircle and nonideal electrode geometry. $C_{\mathrm{dl}}$, represents the capacitive coupling across the electrodeelectrolyte interface. Figure $\underline{9}$ shows the room temperature Nyquist impedance plots of PCL:LiSCN salt complexes with various concentrations of LiSCN. The bulk resistance decreases with increasing LiSCN concentration up to $15 \% \mathrm{wt}$ and then increases with further increasing LiSCN concentration. The bulk resistance $\left(R_{\mathrm{b}}\right)$ of the complexes is obtained from the intercept of the semicircle on the real axis and used to evaluate the electrical conductivity $(\sigma)$ by

$\sigma=1 / R_{b} A$

where $l$ is the thickness of the polymer electrolyte film, $A$ is the electrode area, and $R_{\mathrm{b}}$ is the bulk resistance.

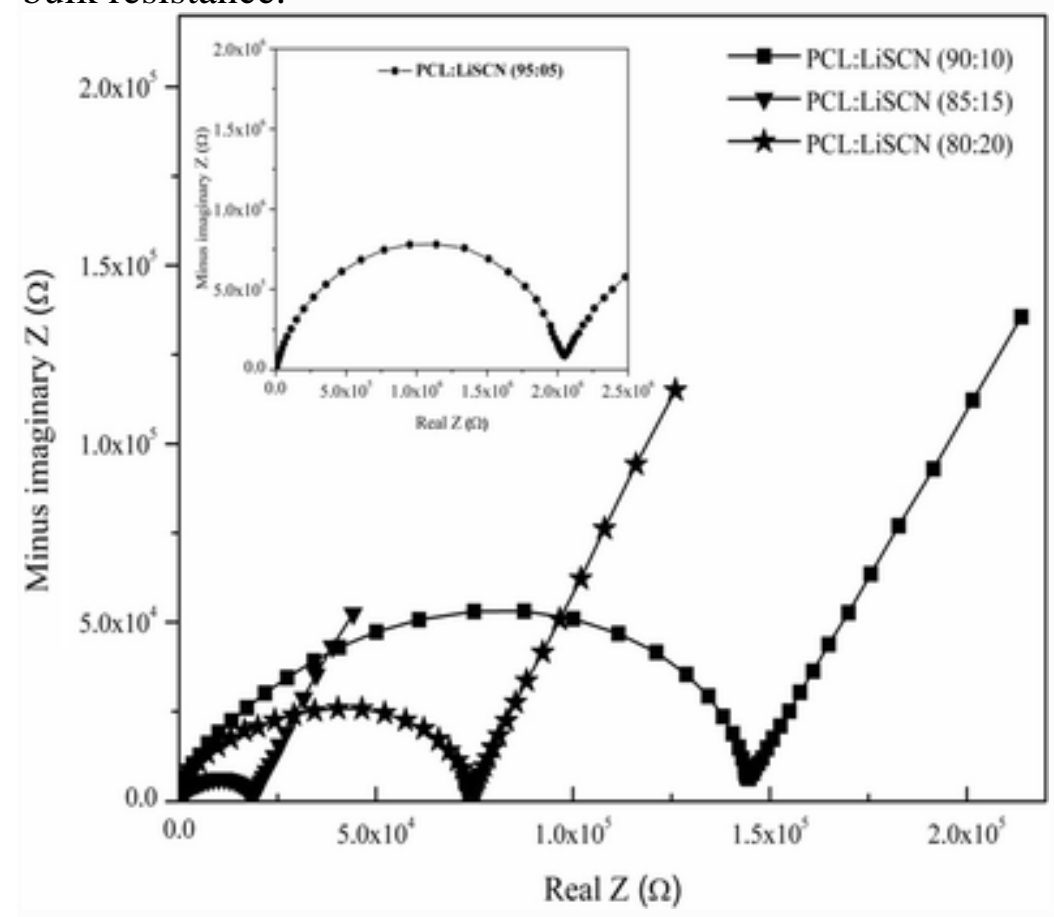

Fig. 9

Nyquist impedance plots for the PCL:LiSCN polymer electrolyte films with different LiSCN contents at $303 \mathrm{~K}$

The salt concentration dependences of room-temperature conductivity are shown in Fig. $\underline{10}$. The electrical conductivity increases with increasing LiSCN content until $15 \mathrm{wt} \%$ and then decreases with further increasing LiSCN content. The maximum electrical conductivity is up to $0.104 \times 10^{-5} \mathrm{~S} \mathrm{~cm}^{-1}$ at room temperature. 


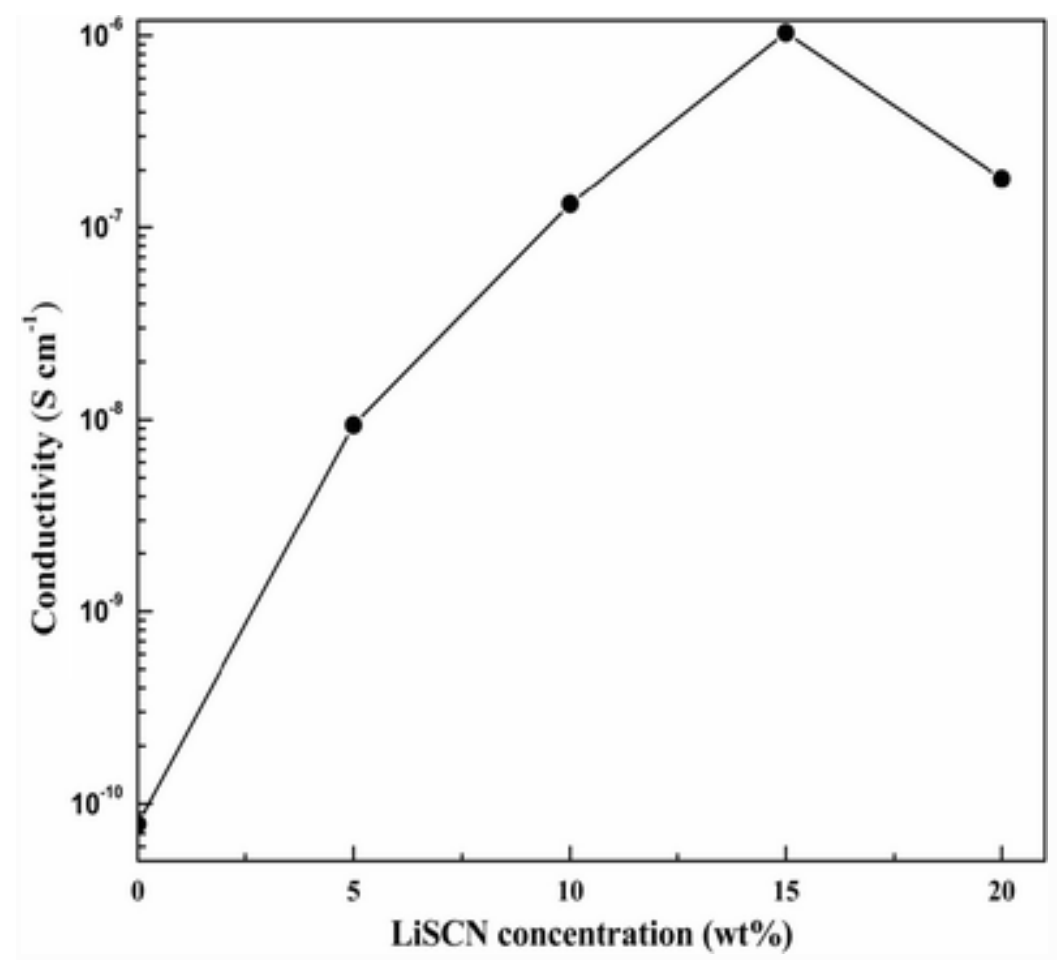

Fig. 10

Variation of ionic conductivity with LiSCN salt concentration at room temperature for the PCL:LiSCN polymer electrolyte films

The improvement in the electrical conductivity can be obtained by enhancing the number of charge carriers $\left(n_{\mathrm{i}}\right)$ and the mobility of charge carriers $\left(\mu_{\mathrm{i}}\right)$ as the electrical conductivity is directly proportional to them according to the equation $\sigma=n_{\mathrm{i}} q_{\mathrm{i}} \mu_{\mathrm{i}}$. At the lower concentration of additives, the number of charge carriers predominantly influences the ionic conductivity, while the mobility of ions and the ionic conduction pathways dramatically affect the ionic conductivity beyond the optimum level. The salt concentration dependent electrical conductivity in the present study confirms the specific interaction of the salt with the polymer host and the influence on its relative crystallinity. The conductivity increase with rising LiSCN content may be ascribed to the increase in the number of mobile charge carriers as well as in the amorphous nature of the polymer electrolyte [37], which is due to the electrostatic coordination interaction of $\mathrm{Li}^{+}$ions with the carbonyl oxygen atoms of PCL. The interaction between $\mathrm{Li}^{+}$ions and carbonyl oxygens of PCL has also been confirmed by the FTIR, and the suppression of crystallinity by XRD and OM. The highest possible ionic conductivity can be achieved when the interaction among $\mathrm{Li}^{+}, \mathrm{SCN}^{-}, \mathrm{LiSCN}$ salt, and polymer structure is balanced because this produces an optimal environment for ionic transport.

The fall of conductivity beyond $15 \mathrm{wt} \%$ LiSCN may be due to three interrelated facts: (a) the high salt concentration acts as a reticulate agent that leads to an increase in the macromolecular rigidity in the amorphous phase of the polymeric matrix, (b) the formation of ion pairs due to a rapid increase in the number of charge carriers as a function of salt concentration, and (c) the development of a crystalline phase by the salt-polymer complex [38].

Figure 11 shows the temperature dependences of ionic conductivity for different PCL:LiSCN polymer electrolyte films. It is evident that $\ln (\sigma)$ increases linearly with increasing reciprocal temperature. This means that the conductivity follows an Arrhenius 
equation $\sigma=\sigma_{0} \exp \left(-E_{\mathrm{a}} / k T\right)$, where $E_{\mathrm{a}}$ is the activation energy for conduction, $\sigma_{0}$ is the preexponential constant, $k$ is the Boltzmann constant and $T$ is the absolute temperature. The linear fitting results, as shown in Table $\underline{3}$, indicate that the activation energy for ionic conduction decreases with increasing LiSCN content up to $15 \mathrm{wt} \%$. The conductivity increases with increasing temperature and this could be caused by the reduced viscosity and the enhanced chain flexibility [39]. This can be explained on the basis of the free volume model [40] and the hopping of charge carriers between localized sites [41]. Polymer chain flexibility is raised with temperature, thereby producing more free volume and making the polymer segments more mobile. The segmental motion either motivates the ions to hop from one site to another or facilitates a pathway for ions to move, thereby resulting in an increase in conductivity. The amorphous phase also leads to the formation of a larger free volume in the polymer matrix with the increase of temperature. At lower temperatures, the dominant crystalline phases make the polymer chains rigid, and thus the ion mobility and the overall conductivity are low. However, at higher temperatures, the amorphous region increases progressively where the polymer chains obtain faster internal modes in which bond rotations produce segmental motion. This can promote the inter- and intra-chain ion hopping movements and thus the conductivity of the polymer electrolyte becomes more pronounced. The variation of activation energy with LiSCN content also indicates the improvement in the amorphous nature of the polymer samples with the addition of salt. It was reported [42] that the low activation energy of ion transportation was due to the high amorphous nature of the polymer electrolytes. It should be noted that a polymer electrolyte with a low value of activation energy and a high value of ionic conductivity is desirable for practical applications.

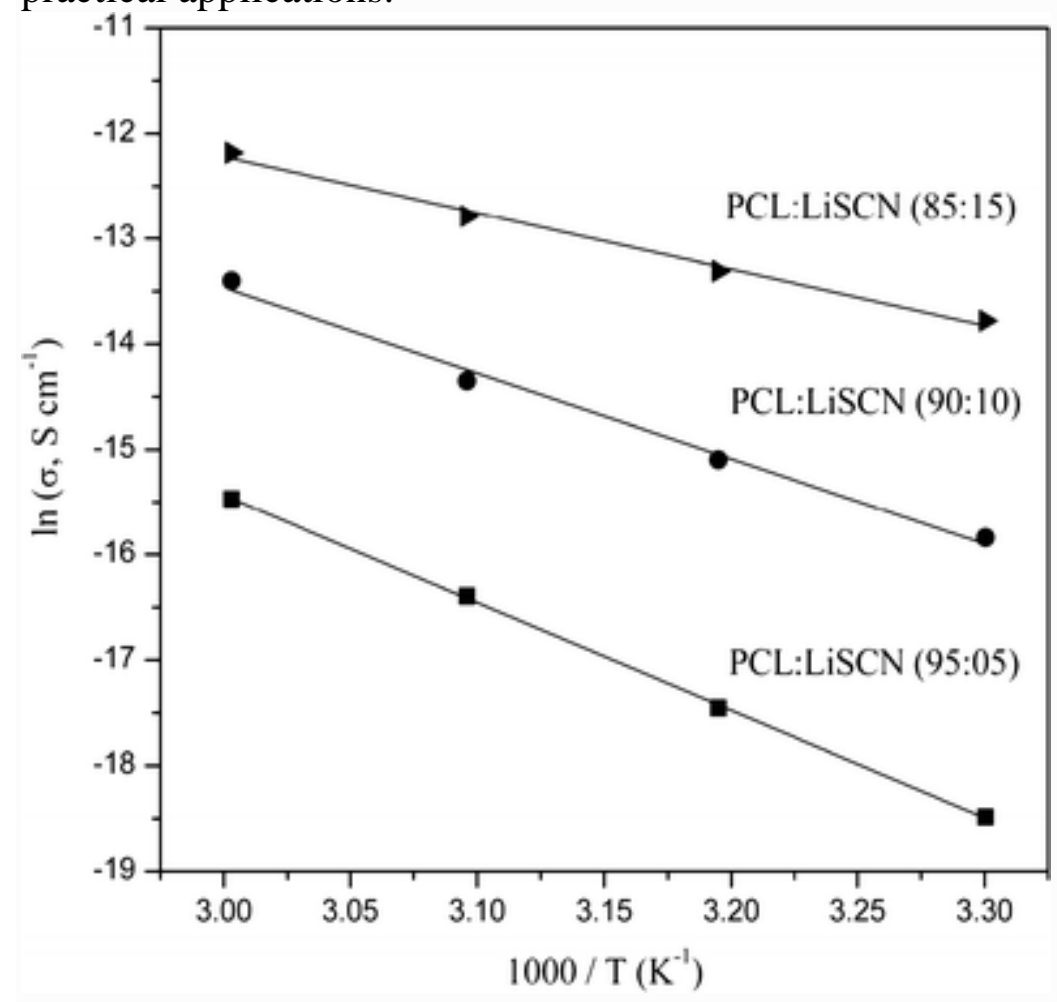

Fig. 11

Natural logarithm of ionic conductivity $(\ln \sigma)$ versus reciprocal temperature $(1 / T)$ for PCL:LiSCN polymer electrolyte films 


\section{Table 3}

Activation energy $\left(E_{\mathrm{a}}\right)$ and pre-exponential constant $\left(\sigma_{0}\right)$ in the Arrhenius equation as well as $R$-square value and optical energy band gaps (both direct and indirect)

\begin{tabular}{|c|c|c|c|c|c|}
\hline \multirow[t]{2}{*}{ Sample } & \multirow[t]{2}{*}{$E_{\mathrm{a}}(\mathrm{eV})$} & \multirow[t]{2}{*}{$\sigma_{0}\left(\mathrm{~S} \mathrm{~cm}^{-1}\right)$} & \multirow{2}{*}{$\begin{array}{l}R \text {-square } \\
\text { value }\end{array}$} & \multicolumn{2}{|c|}{ Band gap $(e V)$} \\
\hline & & & & Direct & Indirect \\
\hline $\begin{array}{l}\text { PCL:LiSCN } \\
(95: 05)\end{array}$ & 0.88 & $3.79 \times 10^{6}$ & 0.999 & 4.99 & 4.88 \\
\hline $\begin{array}{l}\text { PCL:LiSCN } \\
(90: 10)\end{array}$ & 0.69 & $5.22 \times 10^{4}$ & 0.988 & 4.94 & 4.85 \\
\hline $\begin{array}{l}\text { PCL:LiSCN } \\
(85: 15)\end{array}$ & 0.46 & $4.71 \times 10^{1}$ & 0.989 & 4.89 & 4.77 \\
\hline
\end{tabular}

\section{Optical studies}

The study of an optical absorption spectrum gives detailed information about the band structure of the materials. In the absorption process an electron is excited from a lower to higher energy state, by absorbing a photon of known energy in the transmitting radiation. The changes in the transmitted radiation can decide the types of possible electron transitions. The absorption coefficient $\alpha$ may be calculated from the absorbance by $\mathrm{I}=\mathrm{I}_{0} \exp (-\alpha \mathrm{t})$

Hence $\quad \alpha=\frac{2.303}{l} \log \left(I_{0} / I\right)=\frac{2.303}{l} B$

Where $I_{0}$ and $I$ are the intensities of incident and transmitted radiation, respectively, $l$ is the thickness of the film and $B$ corresponds to $\log \left(\mathrm{I}_{0} / \mathrm{I}\right)$.

Generally, in insulators/semiconductors, the electronic transition between the valence and the conduction bands can be direct or indirect. In the direct band gap materials, both the top of the valence band and the bottom of the conduction band are located at the same zero crystal momentum (wave vector). If the bottom of the conduction band does not correspond to the zero crystal momentum, it is called indirect band gap semiconductor. In both cases it can be allowed as permitted by the transition probability $(r)$ or forbidden where no such probability exists. The transitions probability $r$ and absorption coefficient $\alpha$ for amorphous materials are related to the energy of the incident photon as follows [ $\underline{43}, \underline{44}]$.

$$
\begin{aligned}
& (\alpha h v)=C\left(h v-E_{g}\right)^{r} \quad \text { for } h v>E_{g} \\
& (\alpha h v)=0 \quad \text { for } h v<E_{g}
\end{aligned}
$$

where $C$ is a constant equal to $C=4 \pi \sigma_{0} / \mu c \Delta E$, where $\sigma_{0}$ is the dc conductivity, $\Delta E$ is the measure of the extent of band tailing, $\mu$ is the refractive index, $h v$ is the photon energy, $E_{\mathrm{g}}$ is the optical energy band gap, and $r$ is the exponent which can take values of 1 , $2,3,1 / 2$, and $3 / 2$ depending on the nature of the electron transitions, direct or indirect and allowed or forbidden, responsible for the optical absorption. 
For direct and indirect electron transitions the exponent $r$ takes values $1 / 2$ and 2 , respectively. When the direct and indirect band gap exists, the absorption coefficient has the following dependence on the energy of the incident photon.

$$
\begin{aligned}
& (\alpha h v)=C_{1}\left(h v-E_{g d}\right)^{1 / 2} \\
& (\alpha h v)=C_{2}\left(h v-E_{g i}\right)^{2}
\end{aligned}
$$

where $E_{\mathrm{gd}}$ is the direct band gap, $E_{\mathrm{gi}}$ is the indirect band gap, and $C_{1}$ and $C_{2}$ are constants.

Figures $\underline{12}$ and $\underline{13}$ show the $(\alpha h v)^{2}$ and $(\alpha h v)^{1 / 2}$ versus photon energy $(h v)$ for different PCL:LiSCN complexed polymer electrolyte films. The direct and indirect band gap values may be obtained by extrapolating the linear portions of $(\alpha h v)^{2}$ and $(\alpha h v)^{1 / 2}$ versus photon energy $(h v)$ to zero absorption value. The evaluated band gap values are listed in Table $\underline{3}$. It is clear from Table $\underline{3}$ that the direct and indirect energy band gap values decreases with increasing LiSCN salt content. LiSCN salt concentration increases the disorderness of the polymer structure which results in an increase in the optical band gap value. The observed results are in agreement with those obtained from XRD, OM, and conductivity studies in the present work. Furthermore, the decreasing trend of energy band gap with salt concentration is similar to that of activation energy obtained from conductivity studies. The activation energies obtained from conductivity data are small in comparison with the optical band gap energies. This is due to the fact that the nature of these energies is different. The activation energy corresponds to the energy required for conduction of ions from one site to another, where as the optical band gap corresponds to inter-band transition of electrons [45].

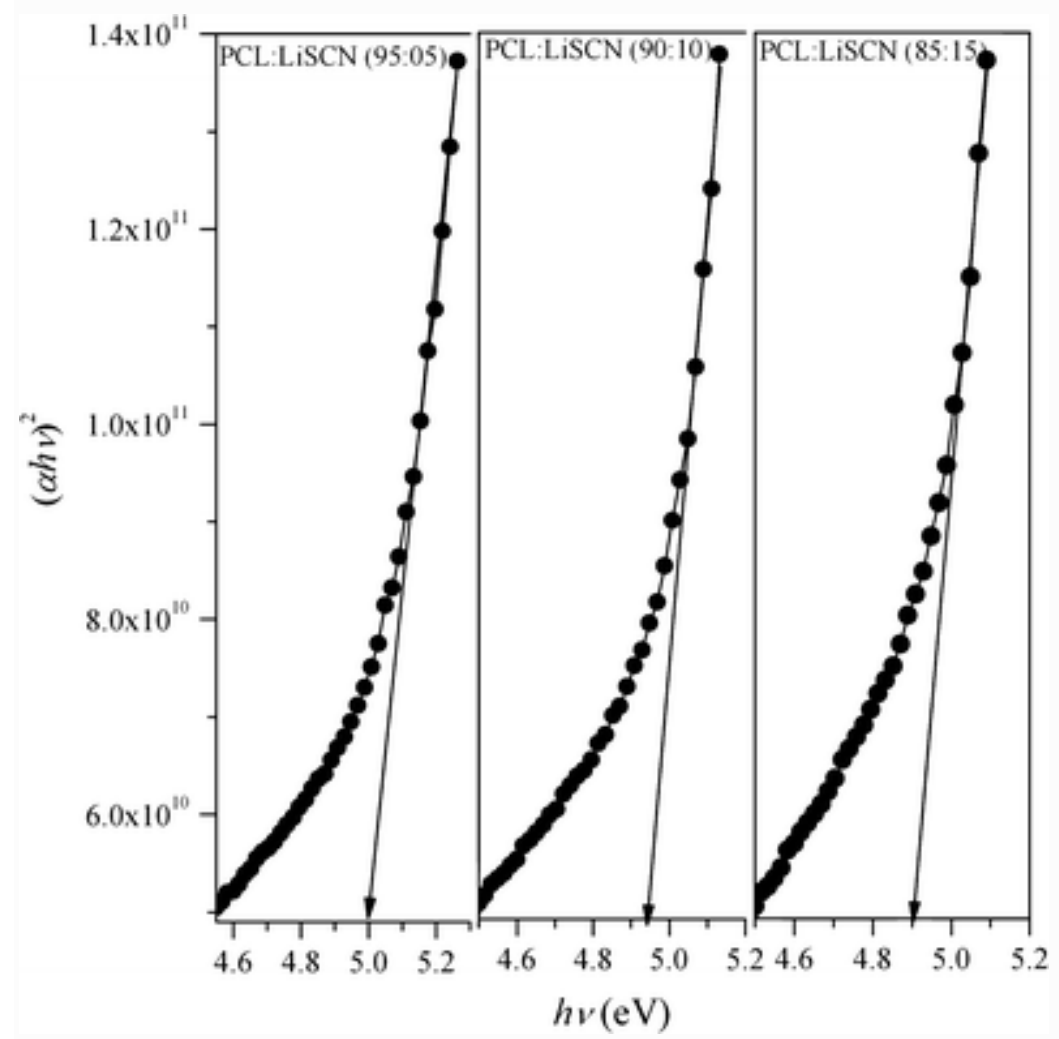

Fig. 12

$(\alpha h v)^{2}$ versus $h v$ plots of PCL:LiSCN complex polymer electrolyte films 


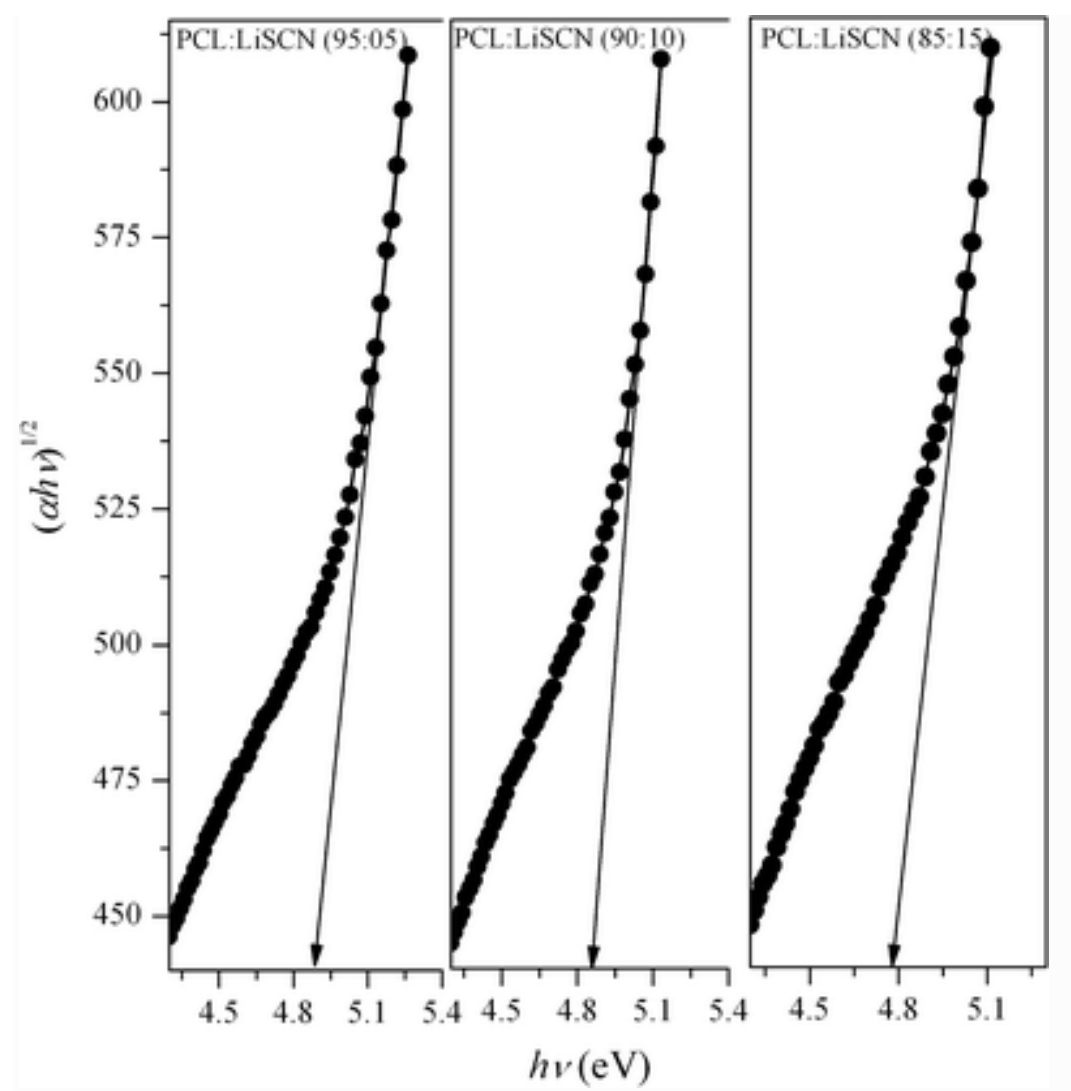

Fig. 13

$(\alpha h v)^{1 / 2}$ versus $h v$ plots of PCL:LiSCN complex polymer electrolyte films

So far, there have been quite a few studies concerning the electrical conductivity of PCLmetal salt complex polymer electrolytes. Polo Fonseca et al. $[\underline{17}, \underline{46}, \underline{47}]$ prepared different $\mathrm{PCL}-\mathrm{LiX}\left(\mathrm{X}=\mathrm{BF}_{4}, \mathrm{ClO}_{4}\right.$, and $\left.\mathrm{CF}_{3} \mathrm{SO}_{3}\right)$ complexed polymer electrolyte films with different salt concentrations $(2,6,10$, and $12 \mathrm{wt} \%)$ by solution cast technique and studied their electrical properties. Their findings showed that the optimum salt concentration for ionic conduction were $12 \mathrm{wt} \% \mathrm{LiBF}_{4}, 10 \mathrm{wt} \% \mathrm{LiClO}_{4}$ and $12 \mathrm{wt} \% \mathrm{LiCF}_{3} \mathrm{SO}_{3}$, respectively. The obtained maximum ionic conductivity value was $1.1 \times 10^{-7} \mathrm{~S} \mathrm{~cm}^{-1}$ for the PCL-12 wt\% $\mathrm{LiBF}_{4}, 1.26 \times 10^{-6} \mathrm{~S} \mathrm{~cm}^{-1}$ for the PCL-10 $\mathrm{wt} \% \mathrm{LiClO}_{4}$, and $3.6 \times 10^{-5} \mathrm{~S} \mathrm{~cm}^{-1}$ for the PCL$10 \mathrm{wt} \% \mathrm{LiCF}_{3} \mathrm{SO}_{3}$.

Nuves et al. [48] fabricated a new family of ionic conducting polymer electrolytes based on a $\mathrm{PCL} /$ siloxane biohybride network doped with lithium triflate $\left(\mathrm{LiCF}_{3} \mathrm{SO}_{3}\right)$ in different concentrations by sol-gel method and studied their structure, morphology, thermal and electrical properties. The d-PCL(530) $0.5 \mathrm{LiCF}_{3} \mathrm{SO}_{3}$ sample showed a maximum electrical conductivity of $1.6 \times 10^{-6} \mathrm{~S} \mathrm{~cm}^{-1}$ at $25^{\circ} \mathrm{C}$. Similarly, some other researchers also prepared the PCL/siloxane biohybride network doped with different metal salts in order to improve the performance of electrolytes. The obtained maximum electrical conductivity values in different systems were $9.64 \times 10^{-6} \mathrm{~S} \mathrm{~cm}^{-1}$ for the d-PCL(530) $4.4 \mathrm{LiClO}_{4}$ at $25{ }^{\circ} \mathrm{C}$ [49] and $1 \times 10^{-6} \mathrm{~S} \mathrm{~cm}^{-1}$ for the d-PCL(530) ${ }_{4} \mathrm{KCF}_{3} \mathrm{SO}_{3}$ at $35^{\circ} \mathrm{C}[\underline{50}]$.

Proton conducting polymer electrolytes based on poly ( $\varepsilon$-caprolacone) and complexed with ammonium thiocyanate $\left(\mathrm{NH}_{4} \mathrm{SCN}\right)$ were prepared, and their morphology and electrical properties were studied by Woo et al. [51]. At room temperature, the maximum electrical conductivity of $4.6 \times 10^{-8} \mathrm{~S} \mathrm{~cm}^{-1}$ was obtained for the 74PCL:26NH $4 \mathrm{SCN}$ system. The PEO/PCL:LiCLO 4 complexed blend polymer electrolytes were prepared by Chiu et al. [52] 
and they reported the maximum room-temperature ionic conductivity of $6.3 \times 10^{-7} \mathrm{~S} \mathrm{~cm}^{-1}$ for the 60PEO:15PCL:25LiClO 4 electrolyte. Based on the above, it may be stated that the maximum ionic conductivity value at room temperature $\left(0.104 \times 10^{-5} \mathrm{~S} \mathrm{~cm}^{-1}\right)$ acquired in the present work is well comparable with those available in the literature. It is worth mentioning that the electrical conductivity could be higher because the effective electrode area could be smaller than the apparent electrode area employed in the calculation as the sample-electrode contact is usually not $100 \%$. In the future research, it may be possible to increase this ionic conductivity value up to $\sim 10^{-3} \mathrm{~S} \mathrm{~cm}^{-1}$ by the addition of plasticizers (ethylene carbonate, propylene carbonate, etc.), ionic liquids (1-butyl-3-methylimidazolium hexafluorophosphate $\left(\mathrm{BMIM}^{\left.-\mathrm{PF}_{6}\right)}\right.$, 1-butyl-3-

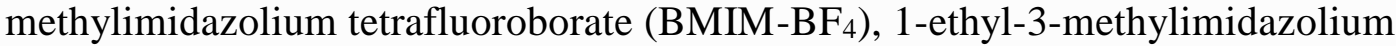
trifluoromethanesulfonate (EMITf), etc.) and nanofillers $\left(\mathrm{TiO}_{2}, \mathrm{Al}_{2} \mathrm{O}_{3}, \mathrm{ZnO}\right.$, etc.) in the $15 \%$ LiSCN-complexed polymer electrolyte system. This magnitude of conductivity will be quite enough for practical ionic device applications [ $[\underline{53}, \underline{54]}$.

\section{Conclusions}

The effect of crystallinity and interaction behavior on the ionic conduction in the biodegradable PCL:LiSCN complexed polymer electrolyte films has been investigated using XRD, OM, FTIR, and AC impedance measurements. The pure PCL possesses a semicrystalline nature and its crystallinity decreases with the addition of LiSCN salt up to $15 \mathrm{wt} \%$, which may be related to the coordination interaction of ions $\left(\mathrm{Li}^{+}\right.$and $\left.\mathrm{SCN}^{-}\right)$with the PCL polymer matrix. The value of ionic conductivity increases with an increase in salt concentration until $15 \mathrm{wt} \%$ but decreases with further salt addition. The $15 \mathrm{wt} \% \mathrm{LiSCN}-$ doped polymer electrolyte exhibits the highest ionic conductivity in value of $0.104 \times 10^{-5} \mathrm{~S} \mathrm{~cm}^{-1}$ at ambient temperature. This may be attributed to the increase in the number density of charge carriers and the decrease in the crystallinity of host polymer. The decrease in ionic conductivity when exceeding $15 \mathrm{wt} \%$ LiSCN salt can be ascribed to the reduction in the mobility of $\mathrm{Li}^{+}$ions and the reorganization of the polymer chains. The temperature-dependent ionic conductivity of the prepared PCL:LiSCN complexes shows an Arrhenius relation and the obtained activation energy for conduction decreases with an increase in LiSCN content up to $15 \mathrm{wt} \%$. Optical energy band gaps (both direct and indirect) show a decreasing trend with increasing LiSCN salt concentration.

\section{Acknowledgments}

This research was supported by the Science and Technology Foundation of Shenzhen.

\section{References}

1. Reddeppa N, Sharma AK, Narasimha Rao VVR, Chen W (2013) Preparation and characterization of pure and $\mathrm{KBr}$ doped polymer blend (PVC/PEO) electrolyte thin films. Microelectron Eng 112:57-62

2. Reddeppa N, Sharma AK, Narasimha Rao VVR, Chen W (2014) AC conduction mechanism and battery discharge characteristics of (PVC/PEO) polyblend films complexed with potassium chloride. Measurement 47:33-41

3. Chiappone A, Nair JR, Gerbaldi C, Bongiovanni R, Zeno E (2015) UV-cured Al2O3laden cellulose reinforced polymer electrolyte membranes for Li-based batteries. Electrochim Acta 153:97-105

4. Wang QJ, Song WL, Fan LZ, Shi Q (2015) Effect of alumina on triethylene glycol diacetate-2-propenoic acid butyl ester composite polymer electrolytes for flexible lithium ion batteries. J Power Sources 279:405-41 
5. Gray FM (1997) Polymer electrolytes, RSC materials monographs. Royal Society of Chemistry, London

6. Hallinan DT Jr, Balsara NP (2013) Polymer electrolytes. Annu Rev Mater Res 43:503525

7. Agrawal RC, Pandey GP (2008) Solid polymer electrolytes: materials designing and allsolid-state battery applications: an overview. J Phys D Appl Phys 41:223001-2230018

8. Manuel Stephan A, Nahm KS (2006) Review on composite polymer electrolytes for lithium batteries. Polymer 47:5952-5964

9. Ulaganathan M, Rajendran S (2010) Preparation and characterizations of PVAc/PVdfHFP)-based polymer blend electrolytes. Ionics 16:515-521

10. Zhong Z, Cao Q, Wang XY, Wu N, Wang Y (2012) PVC-PMMA composite electrospun membranes as polymer electrolytes for polymer lithium ion batteries. Ionics 18:47-53

11. Kiran Kumar K, Ravi M, Pavani Y, Bhavani S, Sharma AK, Narasimha Rao VVR (2012) Electrical conduction mechanism in $\mathrm{NaCl}$ complexed $\mathrm{PEO} / \mathrm{PVP}$ polymer blend electrolytes. J Non-Cryst Solids 358:3205-3211

12. Coombes AGA, Rizzi SC, Williamson M, Barralet JE, Downes S, Wallace WA (2004) Precipitation casting of polycaprolactone for applications in tissue engineering and drug delivery. Biomaterials 25:315-325

13. Ray SS, Bousmina M (2005) Biodegradable polymers and their layered silicate nanocomposites: in greening the 21st century materials world. Prog Mater Sci 50:9621079

14. Patricio T, Gloria A, Bartolo P (2013) Mechanical and biological behaviour of PCL and PCL/PLA scaffolds for tissue engineering applications. Chem Eng Trans 32:1645-1650

15. Gadjourova Z, Andreev YG, Tunstall DP, Bruce PG (2001) Ionic conductivity in crystalline polymer electrolytes. Nature 412:520-523

16. Christie AM, Lilley SJ, Staunton E, Andreev YG, Bruce PG (2005) Increasing the conductivity of crystalline polymer electrolytes. Nature 433:50-53

17. Fonseca CP, Cavalcante F Jr, Amaral FA, Zani Souza CA, Neves S (2007) Thermal and conduction properties of a PCL-biodegradable Gel polymer electrolyte with LiClO4, LiF3CSO3, and LiBF4 salts. Int J Electrochem Sci 2:52-63

18. Teixeira JCS, Fernandes M, de Zea Bermudez V, Barbosa PC, Rodrigues LC, Silva MM, Smith MJ (2010) Mg2+ doped poly (ع-caprolactone)/siloxane biohybrids. Electrochim Acta 55:1328-1332

19. Fernandes M, Nobre SS, Rodrigues LC, Gonçalves A, Rego R, Oliveira MC, Ferreira RAS, Fortunato E, Silva MM, Carlos LD, de Zea Bermudez V (2011) Li+ and Eu3+ doped poly ( $\varepsilon$-caprolactone)/siloxane biohybrid electrolytes for electrochromic devices. ACS Appl Mater Interfaces 3:2953-2965

20. Nuves SC, de Zea Bermudez V, Silva MM, Smith MJ, Morales E, Carlos LD, Sa Ferreira RA, Rocha J (2006) Sol-gel derived Li+ doped poly(E-caprolactone) /siloxane biohybrid electrolytes. J Solid State Electrochem 10:203-210

21. Woo HJ, Majid SR, Arof AK (2011) Conduction and thermal properties of a proton conducting polymer electrolyte based on poly ( $\varepsilon$-caprolactone). Solid State Ionics 199200:14-20

22. Wang YF, Ma XY, Zhang QL, Tian N (2010) Synthesis and properties of gel polymer electrolyte membranes based on novel comb-like methyl methacrylate copolymers. J Membr Sci 349:279-286

23. Khatiwala VK, Shekhar N, Aggarwal S, Mandal UK (2008) Biodegradation of poly( $\varepsilon-$ caprolactone) (PCL) film by Alcaligenes faecalis. J Polym Environ 16:61-67 
24. Lee TH, Boey FYC, Khor KA (1995) X-ray diffraction analysis technique for determining the polymer crystallinity in a polyphenylene sulfide composite. Polym Compos 16:481-488

25. Bhide A, Hariharan K (2007) Ionic transport on (PEO)6:NaPO3 polymer electrolyte plasticized with PEG400. Eur Polym J 43:4253-4270

26. Kumar Y, Hashmi SA, Pandey GP (2011) Ionic liquid mediated magnesium ion conduction in Poly (ethylene oxide) based polymer electrolyte. Electrochim Acta 56:3864-3873CrossRefGoogle Scholar

27. Mitra S, Kulkarni AR (2002) Electrical conductivity studies on the plasticized PEO-DBP$\mathrm{CdX}(\mathrm{X}=\mathrm{Cl}$; SO4) polymer electrolytes. Solid State Ionics 154-155:37-43

28. Nik Aziz NA, Idris NK, Isa NIM (2010) Solid polymer electrolytes based on methylcellulose: FT-IR and ionic conductivity studies. Int J Polym Anal Charact 15:319327

29. Sim LN, Majid SR, Arof AK (2014) Effect of 1-butyl-3methyl imidazolium trifluoromethanesulfonate ionic liquid in poly (ethyl methacrylate)/poly (vinlylidenefluoride-co-hexafluoropropylene) blend based polymer electrolyte system. Electrochim Acta 123:190-197

30. Tamara E, Mohamad NE, Christelle D, Sophie B, Philippe D (2004) FTIR study of polycaprolactone chain organization at interfaces. J Colloid Interface Sci 273:381-387

31. Ahmad S, Bohidar HB, Ahmad S, Agnihotry SA (2006) Role of fumed silica on ion conduction and rheology in nanocomposite polymeric electrolytes. Polymer 47:35833590

32. Wu ID, Chang FC (2007) Determination of the interaction within polyester-based solid polymer electrolyte using FTIR spectroscopy. Polymer 48:989-996r

33. Martin-Vosshage D, Chowdari BVR (1993) Characterization of poly (ethylene oxide) with cobaltbromide. Solid State Ionics 62:205-216

34. Woo HJ, Majid SR, Arof AK (2011) Transference number and structural analysis of proton conducting polymer electrolytes based on ply ( $\varepsilon$-caprolactone). Mater Res Innov 15:51-54

35. Ravi M, Pavani Y, Bhavani S, Sharma AK, Narasimha Rao VVR (2012) Studies on electrical and dielectric properties of PVP:KBrO4 complexed polymer electrolyte films. Mater Chem Phys 130:442-448

36. Poly AR, Kumar R (2014) Ionic conductivity and Dishcarge Characteristic Studies of PVA-Mg(CH3COO)2 Solid Polymer Electrolytes. Int J Polym Mater Polym Biomater 62:76-80

37. Nithya S, Selvasekarapandian S, Karthikeyan S, Inbavalli D, Sikkinthar S, Sanjeeviraja C (2014) AC impedance studies on proton-conducting PAN:NH4SCN polymer electrolytes. Ionics 20:1391-1398

38. Fonseca CP, Neves S (2002) Characterization of polymer electrolytes based on poly (dimethyl silozane-co-ethylene oxide). J Power Sources 104:85-89

39. Ravi M, Pavani Y, Bhavani S, Sharma AK, Narasimha Rao VVR (2012) Investigations on structural and electrical properties of $\mathrm{KClO} 4$ complexed PVP polymer electrolyte films. Int J Polym Mater Polym Biomater 61:309-322

40. Miyamoto T, Shibayama K (1973) Free-volume model for ionic conductivity in polymers. J Appl Phys 44:5372-5376

41. Yang JM, Wang NC, Chiu HC (2014) Preparation and characterization of poly (vinyl alcohol)/sodium alginate blended membrane for alkaline solid polymer electrolytes membrane. J Membr Sci 457:139-148

42. Ramesh S, Arof AK (2001) Ionic conductivity studies of plasticized poly (vinyl chloride) polymer electrolytes. Mater Sci Eng B 85:11-15 
43. Thutupalli GM, Tomlin SG (1976) The optical properties of thin films of cadmium and zinc selenides and tellurides. J Phys D Appl Phys 9:1639-1646CrossRefGoogle Scholar

44. Davis EA, Shalliday TS (1960) Some optical properties of cadmium telluride. Phys Rev 118:1020-1022

45. Mansingh A, Kumar S (1988) Optical properties of As-grown and reduced TeO2 films. Thin Solid Films 161:101-106C

46. Fonseca CP, Rosa DS, Gaboardi F, Neves S (2006) Development of a biodegradable polymer electrolyte for rechargeable batteries. J Power Sources 155:381-384

47. Polo Fonseca C, Neves S (2006) Electrochemical properties of a biodegradable polymer electrolyte applied to a rechargeable lithium battery. J Power Sources 159:712-716

48. Nuves SC, de Zea BV, Ostrovskii D, Martinz NV (2008) Vibrational spectra and microstructure of poly ( $\varepsilon$-caprolactone)/siloxane biohybrides doped with lithium triflate. $\mathrm{J}$ Mol Struct 879:72-80

49. Rodrigues LC, Silva MM, Smith MJ, Goncalves A, Fortunato E (2012) Poly ( $\varepsilon$ caprolactone)/siloxane biohybrids with application in "smart windows". Synth Met 161:2682-2687

50. Fernandes M, Rodrigues LC, Ferreira RAS, Goncalves A, Fortunato E, Silva MM, Smith MJ, Carlos LD, de Zea Bermudes V (2011) K+-doped poly(e-caprolactone)/siloxane biohybrid electrolytes for electrochromic devices. Solid State Ionics 204-205:129-139

51. Woo HJ, Majid SR, Afor AK (2012) Dielectric properties and morphology of polymer electrolytes based on poly ( $\varepsilon$-caprolactone) and ammonium thiocyanate. Mater Chem Phys 134:755-761CrossRefGoogle Scholar

52. Chiu CY, Chen HW, Kuo SW, Huang CF, Chang FC (2004) Investigating the effect of miscibility on the ionic conductivity of LiClO4/PEO/PCL ternary blends. Macromolecules 37:8424-8430

53. Sownthari K, Austin Suthanthiraraj S (2014) Structural, thermal, and electrical studies on gel polymer electrolytes containing 1-ethyl-3-methylimidazolium bis(trifluoromethylsulfonyl) imide. Ionics. doi:10.1007/s11581-014-1324-8

54. Pandey GP, Hashmi SA (2009) Experimental investigations of an ionic-liquid-based, magnesium ion conducting, polymer gel electrolyte. J Power Sources 187:627-634 